\title{
Cyclopoida in Hypersaline Waters of the Crimea and the World: Diversity, the Impact of Environmental Factors, Ecological Role
}

\author{
Elena V. Anufriieva* \\ A.O. Kovalevsky Institute of Marine Biological Research RAS \\ 2 Nakhimov, Sevastopol, 299011, Russia
}

Received 18.03.2016, received in revised form 24.05.2016, accepted 16.10.2016

Summarizing authors' own results and literature data, a brief overview of the Cyclopoida species in hypersaline waters of the Crimea and the world was done. In total, 28 species of cyclops in these extreme conditions were found. Twice representatives of these copepods were observed at salinity up to $300 \mathrm{~g} / \mathrm{L}$. The frequency of cyclops occurrence depends on salinity. It was found that the salinity up to $120-150 \mathrm{~g} / \mathrm{L}$ is not the main factor affecting the presence and abundance of cyclops in water bodies, the more important factors - the level of phytoplankton development and the concentration of osmolytes in its biomass.

Keywords: Cyclopoida, hypersaline lakes, salinity, osmolytes.

DOI: $10.17516 / 1997-1389-2016-9-4-398-408$.

(C) Siberian Federal University. All rights reserved

* Corresponding author E-mail address: lena_anufriieva@mail.ru 


\title{
Суclopoida в гиперсоленых водоемах Крыма и мира: разнообразие, влияние факторов среды, экологическая роль
}

\author{
E.В. Ануфриева \\ Институт морских биологических исследований \\ имени А.О. Ковалевского РАН \\ Россия, 299011, Севастополь, пр. Нахимова, 2
}

Суммируя собственные и литературные данные, дан краткий обзор видов Cyclopoida в гиперсоленых водоемах Крыма и мира. Всего в таких экстремальных условиях найдено 28 видов ииклопов. Дважды представители этих веслоногих ракообразных отмечены при солености 300 г/л. Выявлена статистически значимая отрицательная зависимость частоты встречаемости ииклопообразных от солености. Соленость до 120-150 г/л не является основнылм фактором, влияюшим на наличие и численность рачков в водоемах, более важные факторы уровень развития фитопланктона и концентрация осмолитов в его биомассе.

Ключевые слова: Cyclopoida, гиперсоленые озера, соленость, осмолиты.

8 февраля 2016 г. ушел из жизни выдающийся ученый-копеподолог, академик НАНУ Владислав Иванович Монченко. Статья посвящуается его памяти.

\section{Введение}

Как в воздушной среде насекомые, так в водной среде копеподы - наиболее успешная, разнообразная и многочисленная группа животных (Huys, Boxshall, 1991). В настоящее время известно около $15 \%$ всех существующих на планете видов веслоногих ракообразных, количество которых оценивается в 75-450 тыс. (Humes, 1994; Seifried, 2004; Schminke, 2007). Подсчитано, что суммарная численность Copepoda на Земле более $1,4 \times 10^{21}$ особей, биомасса $46,8 \times 10^{9}$ т, а это больше биомассы человечества в 150 раз (Boxshall, 1998; Schminke, 2007). Уже из этих цифр можно понять ту важную роль, которую копеподы играют в биосфере. Эти рачки освоили практически все водные местообитания планеты. Небольшой процент множества существую- щих копепод, около 40 видов, включая и представителей Cyclopoida, смог освоить и суровые гиперсоленые водоемы (Anufriieva, 2015).

Свободноживущие Cyclopoida являются широко распространенной и многочисленной группой веслоногих ракообразных, около 1000 видов обитает в континентальных водоемах (Boxshall, Defaye, 2008; Hołyńska et al., 2016). Их роль в трофических сетях разнообразна и важна, они формируют сложные индивидуальные консорции с участием паразитических организмов и эпибионтов (Монченко, 1974, 2003; Dieng et al., 2003; Brucet et al., 2009). В морских прибрежных водах Крыма изучение циклопообразных начато в 1860-1870 гг. В. Чернявским, В. Ульяниным, И. Кричагиным, Н. Гребницким, а в континентальных водах они впервые указаны в 1891 г. 
В. Совинским (Монченко, 2003). К настоящему времени в море у берегов Крыма отмечено 18 видов циклопов, а во внутренних водоемах полуострова - 44 (Монченко, 2003; Anufriieva et al., 2014). Фауна Cyclopoida Крыма относится к одной из наиболее изученных в мире, в значительной степени благодаря исследованиям В. Монченко (Монченко, 1974, 2003). Однако в гиперсоленых водоемах Крыма эта группа все еще слабо изучена и данные не обобщены. Это при том, что в Крыму расположено более 50 относительно крупных гиперсоленых озер и множество мелких, они представлены двумя типами - морские (талассогалинные) и континентальные (аталассогалинныесульфатные) (Anufriieva et al., 2014). В настоящее время в степной части Крыма происходит осолонение многих искусственных водоемов, некоторые из них становятся гиперсолеными (Shadrin et al., 2012). В 2011-2015 гг. автор проводила исследования в Крыму, всего было взято и проанализировано 229 проб, из них в гиперсоленых водоемах - 190. Одновременно с отбором проб определяли соленость, температуру, pH. Использованные методы, а также основные результаты были опубликованы ранее (Ануфриева, 2014; Anufriieva et al., 2014; Anufriieva, 2015), поэтому здесь они подробно не описываются.

Цель данной работы - суммируя собственные и литературные данные, дать краткий обзор видов Cyclopoida в гиперсоленых водоемах Крыма и мира, рассмотреть влияние солености, температуры и $\mathrm{pH}$ на таксоцен циклопообразных и их роль в гиперсоленых водоемах.

\section{Разнообразие Cyclopoida \\ в гиперсоленых водоемах}

В гиперсоленых водоемах Крыма найдено 5(6?) видов Cyclopoida (табл. 1), среди котоpых Diacyclops bisetosus (Rehberg, 1880) был наиболее часто встречающимся и массовым. Всего в мире в таких условиях обнаружено не менее 28 видов циклопообразных (табл. 1). При этом 15-16 видов отмечены при солености выше 100 г/л, не менее 9 видов - при 150 г/л и выше и не менее 2 видов - при солености более 300 г/л (табл. 1).

Виды Cyclopoida, которые способны обитать в экстремальных гиперсоленых озеpax, отмечены в 15 родах, в том числе и не связанных близко по происхождению. При изучении палеонтологического материала показано, что у рода Apocyclops способность к существованию в столь суровой среде сформировалась в палеогене или миоцене (Hołyńska et al., 2016). Это позволяет предположить достаточно древнее происхождение механизмов, обеспечивающих их жизнедеятельность в гиперсоленых условиях. Вероятно, эти механизмы возникли независимо в разных группах. Среди циклопов, способных существовать при такой высокой солености, верхний предел галотолерантности у видов пресноводного происхождения выше, чем у видов морского происхождения (табл. 1). Из морских Cyclopoida только представители родов Oithona и Euryte могут обитать при солености до 70-80 г/л (табл. 1).

Насколько хорошо изучена фауна Cyclopoida в гиперсоленых водах мира? Для ответа на этот вопрос, используя собственные данные, рассчитали уравнение зависимости «число обнаруженных видов - количество проанализированных проб» для гиперсоленых вод Крыма (Anufriieva et al., 2014). Рассчитанное уравнение имеет вид $(\mathrm{R}=0,976, \mathrm{p}$ $<0,0005$ )

$$
\mathrm{Y}=2,503 \ln (\mathrm{X})-7,683 \text {, }
$$

где $\mathrm{X}$ - количество просмотренных проб; Y количество найденных видов. 


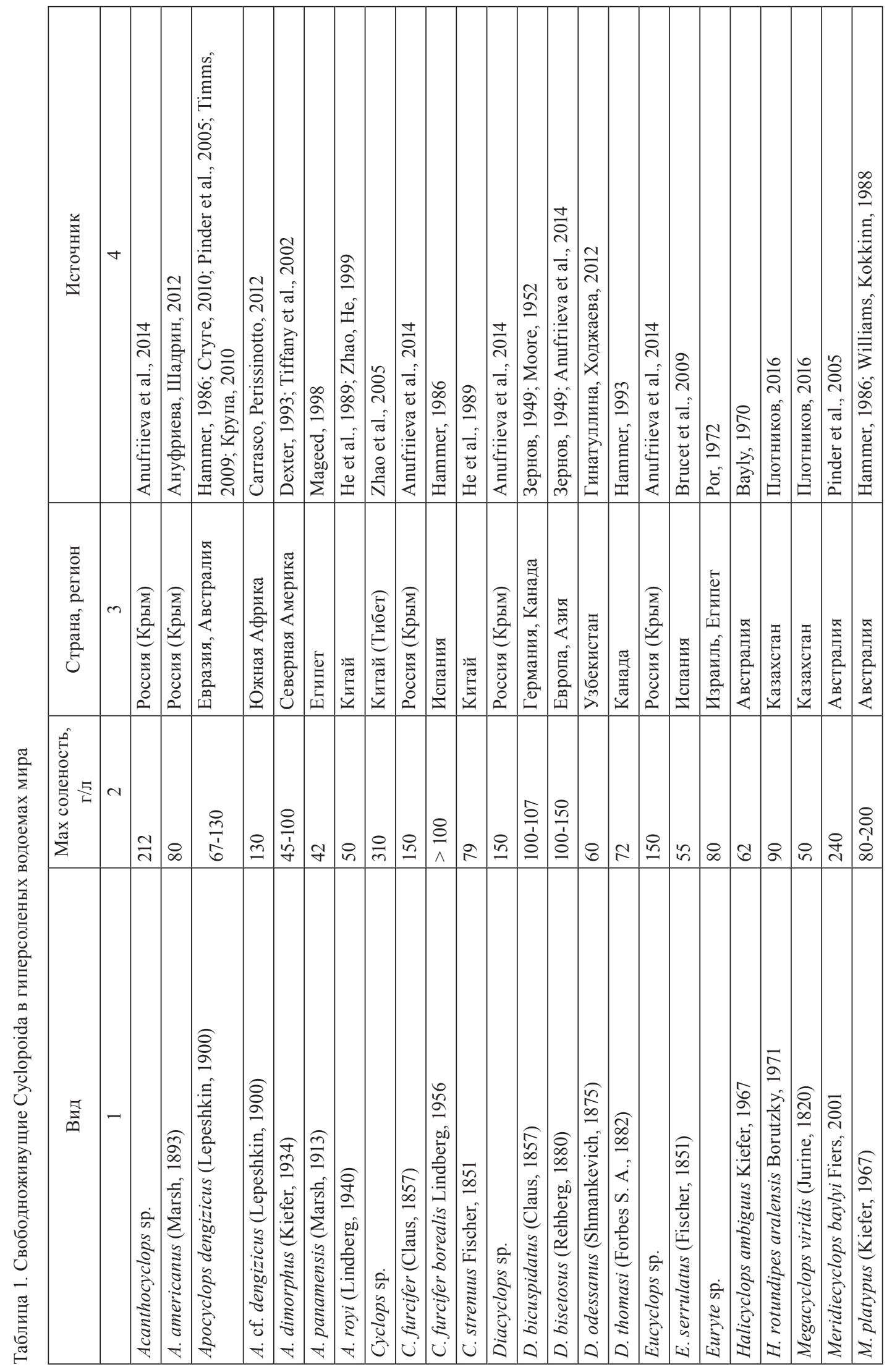




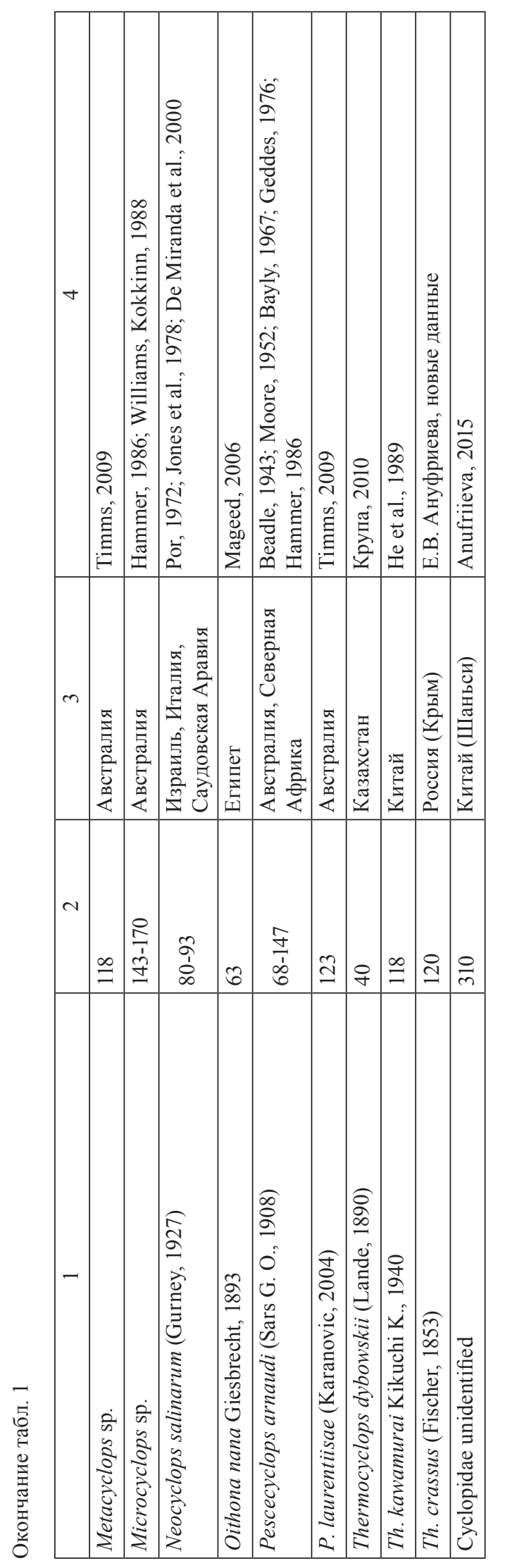


С помощью данного уравнения рассчитали, что при анализе 500 проб можно обнаружить еще около 3-5 видов Cyclopoida (Anufriieva et al., 2014). Если отношение количества найденных видов к количеству ненайденных в гиперсоленых водоемах мира подобно крымскому, то можно ожидать, что в целом не менее 50 видов циклопообразных копепод обитает в гиперсоленых озерах. Однако, учитывая то, что Cyclopoida в гиперсоленых водах Крыма изучены лучше, чем в подобных биотопах других регионов, можно ожидать описания большего количества видов. Если принять во внимание вышесказанное и глобальную тенденцию осолонения водоемов, фаунистические исследования гиперсоленых озер становятся все более актуальными.

Большинство циклопообразных, обитающих в очень соленой среде, имеют большие ареалы, за исключением некоторых эндемичных австралийских видов. Это можно объяснить достаточно древним происхождением видов и наличием у них покоящихся стадий, которые могут распространяться ветром или птицами на большие расстояния (Shadrin, Anufriieva, 2014; Shadrin et al., 2015).

\section{Влияние факторов среды на Cyclopoida \\ в гиперсоленых водоемах}

Данные, полученные в ходе экспедиций по озерам Крымского полуострова, позволили оценить зависимость встречаемости циклопообразных копепод от солености, температуры и рН (Ануфриева, 2014). При разных значениях солености частота их встречаемости была неодинаковой: в пресных водах 83 \%, в диапазоне 2-10 г/л - 69 \%, 11-35 г/л 62,5 \%, 36-100 г/л - 27 \%, 101-150 г/л - $22 \%$, 151-211 г/л - 17 \% и при более высокой солености $-0 \%$. Зависимость частоты встречае- мости Cyclopoida от солености можно описать уравнением $(\mathrm{R}=0,94, \mathrm{p}<0,001)$

$$
\mathrm{Y}=72,8-0,303 \cdot \mathrm{S}
$$

где $\mathrm{Y}$ - частота встречаемости циклопообразных ( \%); $\mathrm{S}$ - соленость (г/л).

Известно, что видовое разнообразие животных в гиперсоленых местообитаниях с ростом солености убывает (Балушкина и др., 2009; Belmonte et al., 2012), этим можно объяснить полученную нами зависимость. Температура также оказывала влияние на частоту встречаемости: при $10-25{ }^{\circ} \mathrm{C}$ она составляла $45 \%$, а при температуре выше $25{ }^{\circ} \mathrm{C}-26 \%$. Частота встречаемости циклопов статистически значимо не зависела от значений $\mathrm{pH}$ в диапазоне 6,0-9,5.

В гиперсоленых озерах Крыма суммарная численность циклопообразных может достигать высоких величин, например, для Diacyclops bisetosus - до 6800 экз/м³ при солености 140 г/л. Численность Apocyclops cf. dengizicus (Lepeshkin, 1900) при солености 100-130 г/л (Южная Африка) временами превышала 10000 экз/ $\mathrm{M}^{3}$ (Carrasco, Perissinotto, 2012). Эта численность циклопов является максимальной из отмеченных при солености выше 100 г/л.

Во всех рассмотренных диапазонах солености вариабельность численности циклопов в водоемах Крыма очень высока (рис. 1a). Это указывает на то, что соленость не единственный фактор, определяющий численность группы в этих водоемах. Не найдена однозначная зависимость численности и от температуры (рис. 1б). Минимальная численность не зависела от температуры, а максимальная - линейно убывала с ее увеличением. Обратная зависимость максимальной численности от температуры статистически значима 

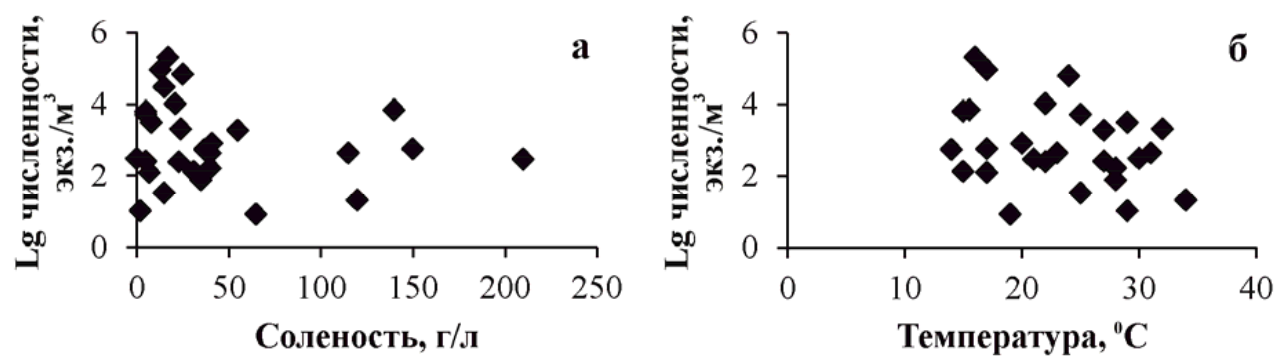

Рис. 1. Влияние солености (а) и температуры (б) на численность Сусlopoida в водоемах Крыма

( $<<0,05)$. Можно сделать вывод, что соленость и температура не являются основными факторами, определяющими наличие и численность циклопообразных в гиперсоленых водоемах.

В гиперсоленой среде большинство видов копепод - осмоконформеры и не имеют механизмов регуляции концентрации солей во внутренних жидкостях организма (Bayly, 1972; Boxshall, Defaye, 2008; Svetlichny, Hubareva, 2014). У животных-осмоконформеров, как и у прокариот, основным механизмом адаптации к осмотическому состоянию внешней среды является синтез или поглощение извне осмопротекторов (совместимых осмолитов) низкомолекулярных органических веществ, которые уравновешивают внешнее давление в цитоплазме, не угнетая метаболизм клетки (Yancey, 2001). Выдвинуто предположение, что копеподы могут получать осмолиты, потребляя микроводоросли (Shadrin, Anufriieva, 2013). Например, часто доминирующая в фитопланктоне гиперсоленых водоемов одноклеточная зеленая водоросль Dunaliella sp. при высокой солености усиливает синтез осмолита-глицерола, концентрация которого в таких условиях может достигать $80 \%$ сухого органического вещества клетки (Ben-Amotz et al., 1982; Chen, Jiang, 2009). Потребляя микроводоросли, животные-осмоконформеры получают достаточно осмолитов, чтобы не тратить свои энергетические ресурсы на их синтез при высокой солености. Можно предположить, что основным фактором, определяющим наличие и численность копепод в гиперсоленых условиях, выступает уровень развития фитопланктона в водоеме и концентрация осмолитов в его биомассе.

\section{Экологическая роль Cyclopoida в гиперсоленых водоемах}

При высокой солености трофическая структура сообществ упрощается и на каждом трофическом уровне количество видов становится небольшим (Иванова, 1990; Williams, 1998; Балушкина и др., 2009; Carrasco, Perissinotto, 2012; Jia et al., 2015). В таких водоемах один вид циклопов нередко является единственным представителем трофического уровня консументов второго порядка. Например, в калифорнийском гиперсоленом озере Солтон-Си вид Apocyclops dimorphus (Kiefer, 1934), ранее ошибочно упоминаемый как A. dengizicus, был основным, практически единственным, потребителем простейших (Tiffany et al., 2007). В оз. Сент-Люсия (Южная Африка) при солености до 130 г/л существовала простейшая экосистема - «один вид на трофический уровень» (Carrasco, Perissinotto, 2012), где ключевую роль играл $A$. cf. dengizicus. В течение 18 месяцев в озере происходило развитие цианобактерии Cyanothece sp., которую потребляла инфузория Fabrea cf. salina Henneguy, 
1890, которую, в свою очередь, поедал циклоп A. cf. dengizicus. Когда концентрация A. cf. dengizicus стала достаточно высокой, в озере стали концентрироваться фламинго и интенсивно поедать циклопов. Массовое развитие и доминирование циклопообразных копепод в гиперсоленых и временами пересыхающих водоемах обусловлено тем, что при неблагоприятных условиях в «спящем» состоянии могут длительно сохраняться не только покоящиеся яйца, но и взрослые особи, находящиеся в состоянии ангидробиоза (Монченко, 1974).

\section{Заключение}

Cyclopoida обитают в гиперсоленых водоемах разных континентов и могут встречаться при солености до 300 г/л. Соленость до 120-150 г/л не является основным фактором, влияющим на наличие и численность циклопов в водоемах. В определенных условиях отдельные виды играют ключевую роль в сообществах гиперсоленых озер. Фаунистические, экологические и физиологические исследования Cyclopoida в гиперсоленых водоемах необходимо продолжать и расширять.

\section{Благодарности}

Работа выполнена при частичной поддержке Otto Kinne Foundation.

Автор выражает глубокую благодарность Н.В. Шадрину и М.К. Холинской за ценные советы и доброжелательную критику при работе над рукописью, О.Ю. Еремину за организацию и проведение экспедиционных работ и рецензентам за внимательное и тщательное прочтение статьи и замечания, которые помогли улучшить рукопись.

\section{Список литературы}

Ануфриева Е.В. (2014) Свободноживущие Cyclopidae (Copepoda, Cyclopoida) в солёных и гиперсолёных водоёмах Крыма: новые находки. Морской экологический журнал, 13 (2): 24-30 [Anufriieva E.V. (2014) Free-living Cyclopidae (Copepoda, Cyclopoida) in saline and hypersaline water bodies of the Crimea: new findings. Marine Ecological Journal [Morskoi ecologicheskii zhurnal], 13 (2): 24-30 (in Russian)]

Ануфриева Е.В., Шадрин Н.В. (2012) Разнообразие ракообразных в гиперсоленом озере Херсонесское (Крым). Экосистемы, их оптимизация и охрана, 7: 55-61 [Anufriieva E.V., Shadrin N.V. (2012) Crustacean diversity in hypersaline Chersonessus Lake (Crimea). Optimization and Protection of Ecosystems [Ehkosistemy, ih optimizaciya i ohrana], 7: 55-61 (in Russian)]

Балушкина Е.В., Голубков С.М., Голубков М.С., Литвинчук Л.Ф., Шадрин Н.В. (2009) Влияние абиотических и биотических факторов на структурно-функциональную организацию экосистем соленых озер Крыма. Журнал общей биологии, 70 (6): 504-514 [Balushkina E.V., Golubkov S.M., Golubkov M.S., Litvinchuk L.F., Shadrin N.V. (2009) Effect of abiotic and biotic factors on the structural and functional organization of the saline lake ecosystems. Biology Bulletin Reviews [Zhurnal obshchei biologii], 70 (6): 504-514 (In Russian)]

Гинатуллина Е.Н., Ходжаева Г.А. (2012) Зоопланктон мелких дренажных озер нижнего течения реки Амударьи в условиях повышенной минерализации воды. Водному сотрудничеству стран Центральной Азии - 20 лет: опыт прошлого и задачи будущего. Тез. докл. междунар. конф. Алматы, с. 173-175 [Ginatullina E.N., Khodjaeva G.A. (2012) Zooplankton of small drainage lakes in lower part of Amudaria under increasing salinity. Twenty Years of Water Cooperation among

$$
-405-
$$


the Central Asian Countries: Past Experience and Future Challenges. Abstracts. Almaty, p. 173-175 (in Russian)]

Зернов С.А. (1949) Общая гидробиология. М., Изд-во АН CCСР, 587 с. [Zernov S.A. (1949) General Hydrobiology. Moscow, Akad. Nauk USSR, 587 p. (in Russian)]

Иванова М.Б. (1990) О зоопланктоне гипергалинных озер. Гидробиологический журнал, 26 (5): 3-9 [Ivanova M.B. (1990) On zooplankton of hypersaline lakes. Hydrobiological Journal [Gidrobiologicheskii Zhurnal], 26 (5): 3-9 (in Russian)]

Крупа Е.Г. (2010) Структура зоопланктона экологически разнотипных водоемов и водотоков Казахстана. Автореф. дис. ... д-ра биол наук: 03.00.08. Алматы, 38 с. [Krupa E.G. (2010) Zooplankton structure of different ecological type's waterbodies and rivers of Kazakhstan. Abstract of Doctor thesis in Biology: 03.00.08. Almaty, 38 p. (in Russian)]

Монченко B.I. (1974) Щелепнороті ииклопоподібні, ииклопи (Cyclopidae). Фауна України. 27 (3). Київ, Наукова думка, 452 с. [Monchenko V.I. (1974) Cyclopidae fauna of the Ukraine. 27 (3). Kiev, Naukova Dumka, 452 p. (in Ukrainian)]

Монченко В.И. (2003) Свободноживущие ииклопообразные копеподы Понто-Каспийского бассейна. Киев, Наукова думка, 350 с. [Monchenko V.I. (2003) Free-living cyclopoid copepods of Ponto-Caspian basin. Kiev, Naukova Dumka, 350 p. (in Russian)]

Плотников И.С. (2016) Многолетние изменения фауны свободноживущих водных беспозвоночных Аральского моря. СПб., ЗИН РАН, 168 с. [Plotnikov I.S. (2016) Long-term changes of aquatic free-living invertebrate fauna in the Aral Sea. St. Petersburg, Zoological Institute of Russian Academy of Sciences, 168 p. (in Russian)]

Стуге T.C. (2010) Распространение и уровень развития Apocyclops dengizicus (Lepeschkin, 1900) (Crustacea: Copepoda: Cyclopoida) в водоемах Казахстана. Selevinia: 175-177 [Stuge T.S. (2010) Distribution and population density of Apocyclops dengizicus (Lepeschkin, 1900) (Crustacea: Copepoda: Cyclopoida) in the water bodies of Kazakhstan. Selevinia: 175-177 (in Russian)]

Anufriieva E.V. (2015) Do copepods inhabit hypersaline waters worldwide? A short review and discussion. Chinese Journal of Oceanology and Limnology, 33 (6): 1354-1361

Anufriieva E., Hołyńska M., Shadrin N. (2014) Current invasions of Asian Cyclopid species (Copepoda: Cyclopidae) in Crimea, with taxonomical and zoogeographical remarks on the hypersaline and freshwater fauna. Annales Zoologici, 64: 109-130

Bayly I.A.E. (1967) The fauna and chemical composition of some athalassic saline waters in New Zealand. New Zealand Journal of Marine and Freshwater Research, 1 (2): 105-117

Bayly I.A.E. (1970) Further studies on some saline lakes of southeast Australia. Australian Journal of Marine \& Freshwater Research, 21 (2): 117-129

Bayly I.A.E. (1972) Salinity tolerance and osmotic behavior of animals in athalassic saline and marine hypersaline waters. Annual Review of Ecology, Evolution, and Systematics, 3 (1): 233-268

Beadle L.C. (1943) An ecological survey of some inland saline waters of Algeria. Journal of the Linnean Society of London, Zoology, 41 (278): 218-242

Belmonte G., Moscatello S., Batogova E.A., Pavlovskaya T., Shadrin N.V., Litvinchuk L.F. (2012) Fauna of hypersaline lakes of the Crimea (Ukraine). Thalassia Salentina, 34: 11-24

Ben-Amotz A., Sussman I., Avron M. (1982) Glycerol production by Dunaliella. Experientia, 38 (1): $49-52$ 
Boxshall G.A. (1998) Preface. Philosophical Transactions of the Royal Society of London, B, Biological Sciences, 353: 669-670

Boxshall G.A., Defaye D. (2008) Global diversity of copepods (Crustacea: Copepoda) in freshwater. Hydrobiologia, 595 (1): 195-207

Brucet S., Boix D., Gascon S., Sala J., Quintana X.D., Badosa A., Søndergaard M., Torben L., Lauridsen T.L., Jeppesen E. (2009) Species richness of crustacean zooplankton and trophic structure of brackish lagoons in contrasting climate zones: north temperate Denmark and Mediterranean Catalonia (Spain). Ecography, 32 (4): 692-702

Carrasco N.K., Perissinotto R. (2012) Development of a halotolerant community in the St. Lucia Estuary (South Africa) during a hypersaline phase. PLoS ONE, 7 (1): e29927.

Chen H., Jiang J.G. (2009) Osmotic responses of Dunaliella to the changes of salinity. Journal of Cellular Physiology, 219 (2): 251-258

De Miranda M.A., Durante L., Serra E. (2000) Zoocenoses dans les bassins de prémiere evaporation dans une saline de la Sardaigne. Mediterránea Serie de Estudios Biológicos, Época II, 17: 45-50

Dexter D.M. (1993) Salinity tolerance of the copepod Apocyclops dengizicus (Lepeschkin, 1900), a key food chain organism in the Salton Sea, California. Hydrobiologia, 267 (1-3): 203-209

Dieng H., Boots M., Tuno N., Tsuda Y., Takagi M. (2003) Life history effects of prey choice by copepods: implications for biocontrol of vector mosquitoes. Journal of the American Mosquito Control Association, 19: 67-73

Geddes N.C. (1976) Seasonal fauna of some ephemeral saline waters in western Victoria with particular reference to Parartemia zietziana Sayce (Crustacea: Anostraca). Australian Journal of Marine \& Freshwater Research, 27 (1): 1-22

Hammer U.T. (1986) Saline lake ecosystems of the world. Dordrecht, Springer, $632 \mathrm{p}$.

Hammer U.T. (1993) Zooplankton distribution and abundance in saline lakes of Alberta and Saskatchewan, Canada. International Journal of Salt Lake Research, 2 (2): 111-132

He Zh.H., Qin J., Wang H., Wang Z.H., Xia X. (1989) Studies on the saline and hypersaline zooplanktons from Jinnan and Yinchuan regions. Acta Hydrobiologica Sinica, 13: 24-37

Hołyńska M., Leggitt L., Kotov A.A. (2016) Miocene cyclopid copepod from a saline paleolake in Mojave, California. Acta Palaeontologica Polonica, 61 (2): 345-361. http://dx.doi.org/10.4202/ app.00137.2014

Humes A.G. (1994) How many copepods? Hydrobiologia, 292 (1): 1-7

Huys R., Boxshall G.A. (1991) Copepod evolution. Vol. 159. London, The Ray Society, 468 p.

Jia Q., Anufriieva E., Liu X., Kong F., Zheng M., Shadrin N. (2015) Intentional introduction of Artemia sinica (Anostraca) in the high-altitude Tibetan Lake Dangxiong Co: the new population and consequences for the environment and for humans. Chinese Journal of Oceanology and Limnology, 33 (6): 1451-1460

Jones D.A., Price A.R.G., Hughs R.N. (1978) Ecology of the high saline lagoons Dawhat as Sayh, Arabian Gulf, Saudi Arabia. Estuarine and Coastal Marine Science, 6 (3): 253-262

Mageed A.A.A. (1998) Distribution and salinity ranges of zooplankton organisms at El-Fayoum Depression (El-Fayoum-Egypt). Egyptian Journal of Aquatic Biology and Fisheries, 2: 51-71

Mageed A.A.A. (2006) Spatio-temporal variations of zooplankton community in the hypersaline lagoon of Bardawil, North Sinai, Egypt. Egyptian Journal of Aquatic Research, 32 (1): 168-183

$$
-407-
$$


Moore J.E. (1952) The Entomostraca of southern Saskatchewan. Canadian Journal of Zoology, 30 (6): 410-450

Pinder A.M., Halse S.A., McRae J.M., Shiel R.J. (2005) Occurrence of aquatic invertebrates of the wheatbelt region of Western Australia in relation to salinity. Hydrobiologia, 543 (1): 1-24

Por F.D. (1972) The benthic Copepoda of the Sirbonian Lagoon (Sabkhat el Bardawil). Cahiers de Biologie Marine, 14: 89-107

Schminke H.K. (2007) Entomology for the copepodologist. Journal of Plankton Research, 29 (suppl 1): 149-162

Seifried S. (2004) The importance of a phylogenetic system for the study of deep-sea harpacticoid diversity. Zoological Studies, 43 (2): 435-445

Shadrin N., Anufriieva E., Galagovets E. (2012) Distribution and historical biogeography of Artemia Leach, 1819 (Crustacea: Anostraca) in Ukraine. International Journal of Artemia Biology, 2: $30-42$

Shadrin N.V., Anufriieva E.V. (2013) Dependence of Arctodiaptomus salinus (Calanoida, Copepoda) halotolerance on exoosmolytes: new data and a hypothesis. Journal of Mediterranean Ecology, 12: 21-26

Shadrin N.V., Anufriieva E.V. (2014) Resting stages of crustaceans in the Crimean hypersaline lakes (Ukraine) and their ecological role. Acta Geologica Sinica, 88 (supp. 1): 46-49

Shadrin N.V., Anufriieva E.V., Amat F., Eremin O.Yu. (2015) Dormant stages of crustaceans as a mechanism of their existence in an extreme unpredictable environment of the Crimean hypersaline lakes. Chinese Journal of Oceanology and Limnology, 33 (6): 1362-1367

Svetlichny L., Hubareva E. (2014) Salinity tolerance of alien copepods Acartia tonsa and Oithona davisae in the Black Sea. Journal of Experimental Marine Biology and Ecology, 461: 201-208

Tiffany M.A., Swan B.K., Watts J.M., Hurlbert S.H. (2002) Metazooplankton dynamics in the Salton Sea, California, 1997-1999. Hydrobiologia, 473: 103-120

Tiffany M.A., Swan B.K., Gebler G.F., Cole J.C., Gonzalez M.R., Reifel K.M., Watts J.M., Small E.B., Hurlbert S.H. (2007) Ciliate plankton dynamics and survey of ciliate diversity in the Salton Sea, California, 1997-1999. Lake and Reservoir Management, 23 (5): 606-619

Timms B.V. (2009) Study of the saline lakes of the Esperance Hinterland, Western Australia, with special reference to the roles of acidity and episodicity. Natural Resources and Environmental Issues, 15 (1): $215-225$

Williams W.D. (1998) Salinity as a determinant of the structure of biological communities in salt lakes. Hydrobiologia, 381 (1-3): 191-201

Williams W.D., Kokkinn M.J. (1988) The biogeographical affinities of the fauna in episodically filled salt lakes: a study of Lake Eyre South, Australia. Hydrobiologia, 158 (1): 227-236

Yancey P.H. (2001) Water stress, osmolytes and proteins. American Zoologist, 41: 699-709

Zhao W., He Zh. (1999) Biological and ecological features of inland saline waters in North Hebei, China. International Journal of Salt Lake Research, 8: 267-285

Zhao W., Zheng M., Xu X., Liu X., Guo G., He Zh. (2005) Biological and ecological features of saline lakes in northern Tibet, China. Hydrobiologia, 541: 189-203 